\title{
A ESTÉTICA DA OBRA DE ARTHUR BISPO DO ROSÁRIO
}

\section{ARTIGO ORIGINAL}

SÁ, Roberta Mendes De ${ }^{1}$

SÁ, Roberta Mendes De. Et al. A estética da obra de Arthur Bispo do Rosário. Revista Científica Multidisciplinar Núcleo do Conhecimento. Ano 05, Ed. 11, Vol. 17, pp. 27-44. Novembro de 2020. ISSN: 2448-0959, Link de acesso: https://www.nucleodoconhecimento.com.br/arte/estetica-da-obra

\section{RESUMO}

Este artigo apresenta a obra do artista Arthur Bispo do Rosário, que foi interno do hospital psiquiátrico da Colônia Juliano Moreira, no Rio de Janeiro. O objetivo é analisar os elementos estéticos da obra de Arthur Bispo do Rosário, compreendendo sua poética e simbologia. Os conceitos de estética são analisados através das narrativas de Bourriaud, Hegel e Suassuna. A obra e a poética de Arthur Bispo do Rosário são analisadas através das narrativas de Dantas, Dionisio, Foucault, Hidalgo, Lazaro e Silva. A metodologia empregada neste artigo nasce da perspectiva desses autores para compreender a estética e simbologia da obra de Arthur Bispo do Rosário.

Palavras-chave: Arthur Bispo do Rosário, estética, poética.

\section{INTRODUÇÃO}

Este artigo tem como objetivo analisar a estética da obra do artista Arthur Bispo do Rosário, que foi interno do hospital psiquiátrico da Colônia Juliano Moreira, no Rio de Janeiro, e desenvolveu uma poética particular em suas obras, tendo como referência a religiosidade, cotidiano e os elementos de sua vida, aproveitando-se dos materiais em seu entorno.

\footnotetext{
${ }^{1}$ Mestranda em História da Arte pela Universidade Federal de São Paulo - UNIFESP.
} 
Escolhi este tema devido à história de vida do artista, que desenvolveu a sua obra dentro do hospital psiquiátrico, contendo uma poética particular e simbólica.

A obra de Bispo do Rosário é pura no sentido de fazer dessa arte personagens, narrativas, temas, metáforas e níveis de leitura e de significativas, articulados num jogo, tanto complexo quanto fugitivo, entre a realidade e a imaginação. (LAZARO, 2012, p. 21)

Conforme Silva (2003), Arthur Bispo do Rosário nasceu em Japaratuba (SE), sendo controversa a sua data de nascimento, pois diferentes registros apontam o ano de 1909 ou 1911, assim como detalhes da sua biografia antes da internação, sendo comprovado que trabalhou na Marinha de Guerra Brasileira de 1925 a 1933, mudando-se para o Rio de Janeiro, onde trabalhou na Light como lavador de bondes e posteriormente como vulcanizador. Após seu desligamento da Light, trabalhou com serviços gerais na residência do advogado Humberto Leone, que o teria representado em uma causa movida contra essa mesma empresa, demonstrando habilidade manual e capacidade para articulação de objetos.

Ao sofrer o que se supõe seu primeiro delírio, em 22 de dezembro de 1938, Bispo viu Jesus Cristo descer à terra rodeado por uma corte de sete anjos azuis. Vozes Ihe teriam dito para reconstruir o mundo. Consta que vagava pelo Rio de Janeiro por dois dias e duas noites, até ser interceptado pela polícia, que o encaminhou para a primeira internação no Hospital dos Alienados, na Praia Vermelha, Rio de Janeiro. Foi internado em 24 de dezembro desse ano. (SILVA, 2003, p. 37)

Ainda de acordo com Silva (2003), Arthur Bispo do Rosário foi transferido para a Colônia Juliano Moreira, em Jacarepaguá, Rio de Janeiro, em 25 de janeiro de 1939, tendo reingressado em diferentes períodos, talvez por motivo de fugas. Durante os períodos em que não esteve internado, sob o diagnóstico de esquizofrenia paranoide, trabalhou para a família Leone.

A obra de Arthur Bispo do Rosário traz reflexões sobre a forma de expressão de um indivíduo que viveu em uma instituição psiquiátrica e que desenvolveu uma produção artística contemporânea, unindo elementos religiosos e do cotidiano a um profundo significado e ordenação. 
Ele era o senhor da minúcia. Recriava objetos do universo e os titulava: raspadeira, carvão, pedra, rodo. Esmerava-se em relacionar toda sorte de coisas terrenas seguindo a lógica da realidade (afinal, as reproduções dos objetos são simples e reconhecíveis), com uma tendência ao lúdico. (HIDALDO, 2011, p. 91)

Segundo Silva (2003), Arthur Bispo do Rosário faleceu em 05 de julho de 1989, na Colônia Juliano Moreira, tendo a certeza de que havia cumprido a função de servir a Deus e mostrar a salvação.

\section{A ESTÉTICA E A ARTE DE ARTHUR BISPO DO ROSÁRIO}

Conforme Hegel (1996), as obras de arte não são produtos naturais, mas produtos humanos; são criadas para o homem e dirigem-se ao mundo sensível; possuem um fim particular que lhe é imanente.

Ainda de acordo com Hegel (1996), a verdade da arte não se refere à exatidão pura e simples da natureza, mas deve realizar um acordo entre o exterior e o interior, concordando consigo mesmo para que possibilite a revelação exterior.

Dessa forma, a subjetividade do artista e a observação do cotidiano podem estar inseridas na criação artística, revelando para o exterior aquilo que o inquieta, comunicando-se com o mundo através da arte.

"Se se quiser marcar um fim último à arte, será ele o de revelar a verdade, o de representar, de modo concreto e figurado, aquilo que agita a alma humana." (HEGEL, 1996, p. 71)

Para Hegel (1996), o belo artístico é superior ao belo natural por ser um produto do espírito, já que este é superior à natureza.

Segundo Suassuna (2009), nas épocas clássicas, a Estética era definida como a "Filosofia do Belo", e este era uma propriedade do objeto.

O nome Estético passou, então, a designar o campo geral da Estética, que incluía todas as categorias pelas quais os artistas e os pensadores tivessem demonstrado interesse, como o Trágico, o Sublime, o Gracioso, 
o Risível, o Humorístico etc., reservando-se o nome de Belo para aquele tipo especial, caracterizado pela harmonia, pelo senso de medida, pela fruição serena e tranquila - o Belo chamado clássico, enfim. (SUASSUNA, 2009, p. 22)

Ainda de acordo com Suassuna (2009), a Estética não se confunde com a Crítica da Arte e nem poderia legislar sobre a Arte, porque é somente uma atividade reflexiva efetuada sobre os princípios iniciais do campo estético, sobre a Beleza e a Arte, e não sobre o particular e o concreto.

Tendo como ponto de partida essas referências, deve-se considerar que na obra de Arthur Bispo do Rosário, não havia um ideal estético ou acadêmico, tendo como base a sua subjetividade, conceito de mundo e religiosidade, caracterizada com o objetivo de "servir a uma missão", aproveitando-se dos materiais de uso cotidiano, que estavam disponíveis em seu entorno, dentro do hospital psiquiátrico.

A possibilidade de uma arte relacional (uma arte que toma como horizonte teórico a esfera das interações humanas e seu contexto social mais do que a formação de um espaço simbólico autônomo e privado) atesta uma inversão radical dos objetivos estéticos, culturais e políticos postulados pela arte moderna. Em termos Sociológicos gerais, essa evolução deriva sobretudo do nascimento de uma cultura urbana mundial e da aplicação desse modelo citado a praticamente todos os fenômenos culturais. (BOURRIAUD, 2009, p. 19-21)

Assim, os objetos estéticos produzidos por Arthur Bispo do Rosário, continham a sua relação com o mundo particular em que habitava, diferente da realidade que vivenciava como interno do hospital.

A prática do artista, seu comportamento enquanto produtos, determina a relação que será estabelecida com sua obra: em outros termos, o que ele produz, em primeiro lugar, são relações entre as pessoas e o mundo por intermédio dos objetos estéticos. (BOURRIAUD, 2009, p. 59)

De acordo com Silva (2003), nunca houve a certeza de que Arthur Bispo do Rosário se considerava artista ou tinha essa consciência, mas desde a juventude costumava realizar alterações físicas nos lugares em que habitava e demonstrava habilidades manuais com objetos, produzindo apenas para si, a partir de uma pulsão interior, e sem o desejo de expor às outras pessoas as suas obras. 
Dessa forma, são esses os elementos que conduzem a um estudo das narrativas poéticas de Arthur Bispo do Rosário, que perfazem o conjunto de sua obra.

\section{A POÉTICA DA OBRA DE ARTHUR BISPO DO ROSÁRIO}

\subsection{O IMAGINÁRIO ARTÍSTICO E SEUS ELEMENTOS}

Conforme Silva (2003), prevalece na obra de Arthur Bispo do Rosário, a tridimensionalidade, através do desenvolvimento de objetos para a ocupação de espaços nas dimensões do comprimento, largura e altura. Poucos trabalhos foram realizados no plano, como os bordados em lençóis, papéis escritos, e quadros.

Ainda de acordo com Silva (2003), há padrões expressivos que se repetem na obra do artista. Também ocorre uma semelhança entre algumas obras autônomas e as vanguardas do início do século $X X$, mas que não eliminam o caráter de imprevisibilidade e abertura para diversas análises de sua produção artística, que não tem um elemento de expressão único, já que permite o aproveitamento de diversos materiais que se transformam em peças únicas.

Segundo Hidalgo (2011), ao longo das décadas, pacientes levavam a Arthur Bispo do Rosário diversos tipos de sucata, assim como ele mesmo e funcionários compravam quinquilharias diversas no comércio em Jacarepaguá e Madureira.

$\mathrm{Na}$ obra de Arthur Bispo do Rosário, há uma transformação dos objetos do cotidiano em produções artísticas, que refletem características próprias, como a religiosidade, senso de organização, o trabalho na Marinha e o sonho de ser pugilista, dentre outros aspectos.

Pode-se afirmar, sem possibilidade de erro, que a loucura é o elemento positivo no reconhecimento de seu feito como objeto de arte. Se outro a produzisse, fora das condições de Bispo, dificilmente seria reconhecido como grande criador. Posteriormente, desconstruindo-a para a interpretação, verificam-se aspectos autônomos inter-relacionados que, no sentido semântico, falam a partir de quatro proposições que the são características: ordenar, catalogar, preencher, envolver. (SILVA, 2003, p. 60) 
Conforme Hidalgo (2011), Arthur teve uma infância rodeada pela religiosidade característica de uma pequena cidade, como Japaratuba (SE), repleta de alegorias, em que a Folia de Reis trazia com o trabalho das bordadeiras o esplendor das roupas de folguedos, envolvendo as tradições africanas, indígenas e nordestinas. Estas memórias permaneceram na memória do artista, trazendo relações diretas com as suas obras.

Egresso de uma vila cravada por tradições seculares, Bispo lidou das mais criativas formas com a diversidade de fardões, tecidos, adornos, rebordos costurados por mães, tias, avós. Ao se designar rei dos reis, teceria um manto avermelhado só para ele, salpicado de bordados, e se faria coroar, protagonista da própria via sacra. (HIDALGO, 2011, p. 34)

Ainda de acordo com Hidalgo (2011), Arthur realizou a peregrinação ao Mosteiro de São Bento, com o objetivo de se apresentar como o salvador, culminando com a sua primeira internação, em 24 de dezembro de 1938, no hospício da Praia Vermelha.

A loucura começa ali onde se perturba e se obnubila o relacionamento entre o homem e a verdade. É a partir desse relacionamento, ao mesmo tempo que da destruição desse relacionamento, que a loucura assume seu sentido geral e suas formas particulares. (FOUCAULT, 1978, p. 267)

A religiosidade, presente em Arthur Bispo do Rosário, surgia em seus delírios e na criação artística.

FIGURA 1: "A história universal" (s/d), bordado sobre tecido, 138 x $189 \mathrm{~cm}$

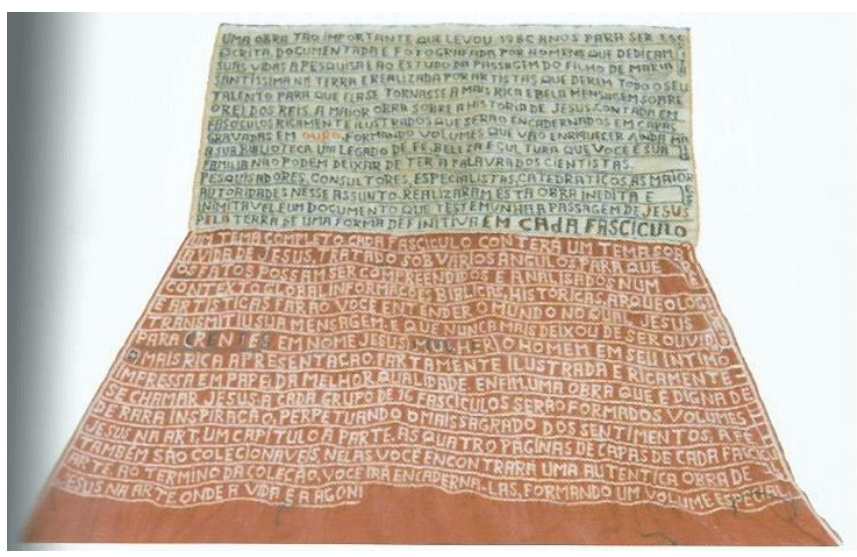

Fonte: DANTAS (2009, p. 175) 
Conforme se percebe na Figura 1, há a relação do bordado com as lembranças da infância e da sua cidade natal, Japaratuba (SE), ligado à questão da religiosidade e sua história.

A loucura encontra-se exatamente no ponto de contato entre o onírico e o erro; ela percorre, em suas variações, a superfície em que ambos se defrontam, a mesma que ao mesmo tempo os separa e une. Com o erro, ela tem em comum a não-verdade e o arbitrário na afirmação ou na negação; ao sonho ela toma de empréstimo a ascensão das imagens e a presença colorida dos fantasmas. Mas enquanto o erro é apenas uma não-verdade, enquanto o sonho não afirma nem julga, a loucura enche de imagens o vazio do erro e une os fantasmas através da afirmação do falso. (FOUCAULT, 1978, p. 268)

Conforme Silva (2003), a característica de preencher o espaço da expressão através dos bordados, dispõe o que se pretende através de uma complementaridade de formas, em que a lacuna é eliminada.

Nessa obra, Arthur Bispo do Rosário parece querer deixar o seu testemunho religioso a todos os que puderem se aproximar de sua obra, perfazendo talvez a sua função de salvador, preenchendo o espaço em branco do tecido com as palavras e frases que estão em seus pensamentos diários.

FIGURA 2: "Colônia Juliano Moreira" (s/d), bordado sobre tecido, 134 x $133 \mathrm{~cm}$

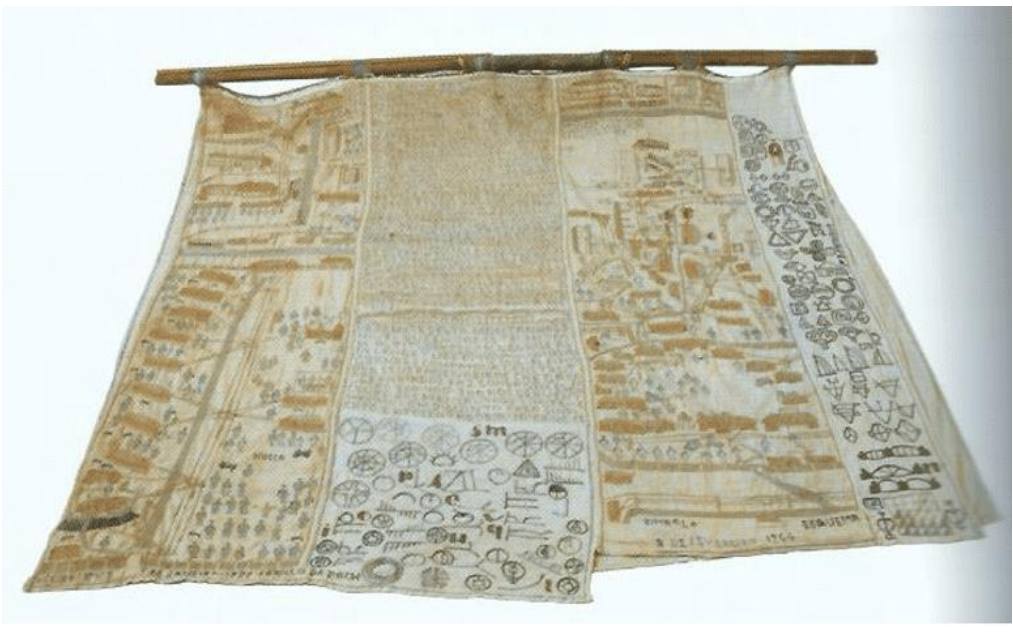

Fonte: DANTAS (2009, p. 188) 
Na Figura 2, Arthur Bispo do Rosário preencheu os espaços em branco do tecido com as suas percepções, utilizando-se dos bordados para retratar a Colônia Juliano Moreira.

Os bordados são elaborados com a técnica do preenchimento do espaço. Um pergaminho de memórias e de representações do entorno buscando a completude nos limites do branco. Preencher aí significa dominar o que está virgem pela inserção de uma gramática pessoal. É formular uma personalidade transformadora, mudando-se a natureza daquilo que é efêmero. Ao se bordar, o pano adquire outra natureza que não a de ser um mero lençol. Sobre ele está a pregnância do signo artístico. (SILVA, 2013, p. 64)

Conforme Silva (2003), o catalogar também está presente na obra de Bispo, através da ordenação espacial, em que se dispõe a memória do passado vivido através de um sistema numérico e de escrita, transposto para o nível estético, que pode representar a vontade de controle sobre o todo.

Dessa forma, é possível compreender o senso de observação do espaço presente na obra de Arthur Bispo do Rosário, com o intuito de demarcar e identificar o ambiente em que vivia, como a Colônia Juliano Moreira.

FIGURA 3: "Grande veleiro" (s/d), madeira, tecido, papelão, cordames, metal, isopor, lâmpada e plástico, $145 \times 60 \times 100 \mathrm{~cm}$, sobre carrinho de madeira com rodas, $70 \times 33$ $x 20 \mathrm{~cm}$

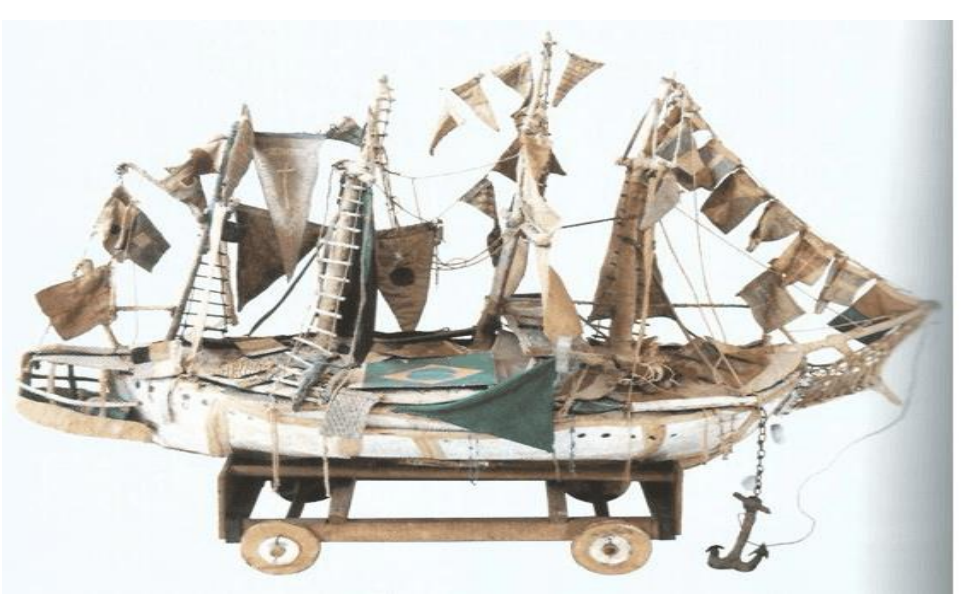

Fonte: DANTAS (2009, p. 190) 
Os barcos, presentes na obra de Arthur, remetem às lembranças da Marinha, como se pode observar na Figura 3.

Conforme Hidalgo (2011), a decoração dos navios construídos por Arthur Bispo do Rosário era repleta por bandeirolas, pois como trabalhou como sinaleiro na Marinha, agitava em cada mão uma bandeirola vermelha e outra azul, emitindo sinais variados para se comunicar com as esquadras. As bandeiras em suas obras representavam também diversos países.

Bispo iniciou a série em madeira nos Leoni e a aperfeiçoou na clínica. Colhia cabos de vassoura, ripas de madeira e quinquilharias para construir variações estéticas em torno da Marinha. Era a memória do exmarinheiro, sufocada, que acorria. Ele rebobinava o cérebro em busca de pormenores das embarcações em que navegara, mastros, escadas, arrastões, bóias, botes salva-vidas, bandeiras, âncora. (HIDALGO, 2011, p. 65)

Todos esses elementos representam a importância que as memórias da Marinha desempenhavam na obra de Arthur Bispo do Rosário, guardadas em sua subjetividade e detentoras de diversas metáforas, talvez com o sentido de se utilizar das imagens dos barcos e bandeiras como condutores da religiosidade e da própria vida. 
FIGURA 4: "Talheres assemblage" (s/d), com 49 colheres de sopa, dez colheres de chá, quatro de café, cinco de sobremesa, dez garfos e seis facas em metais diversos, suporte de madeira e papelão, $197 \times 70 \mathrm{~cm}$

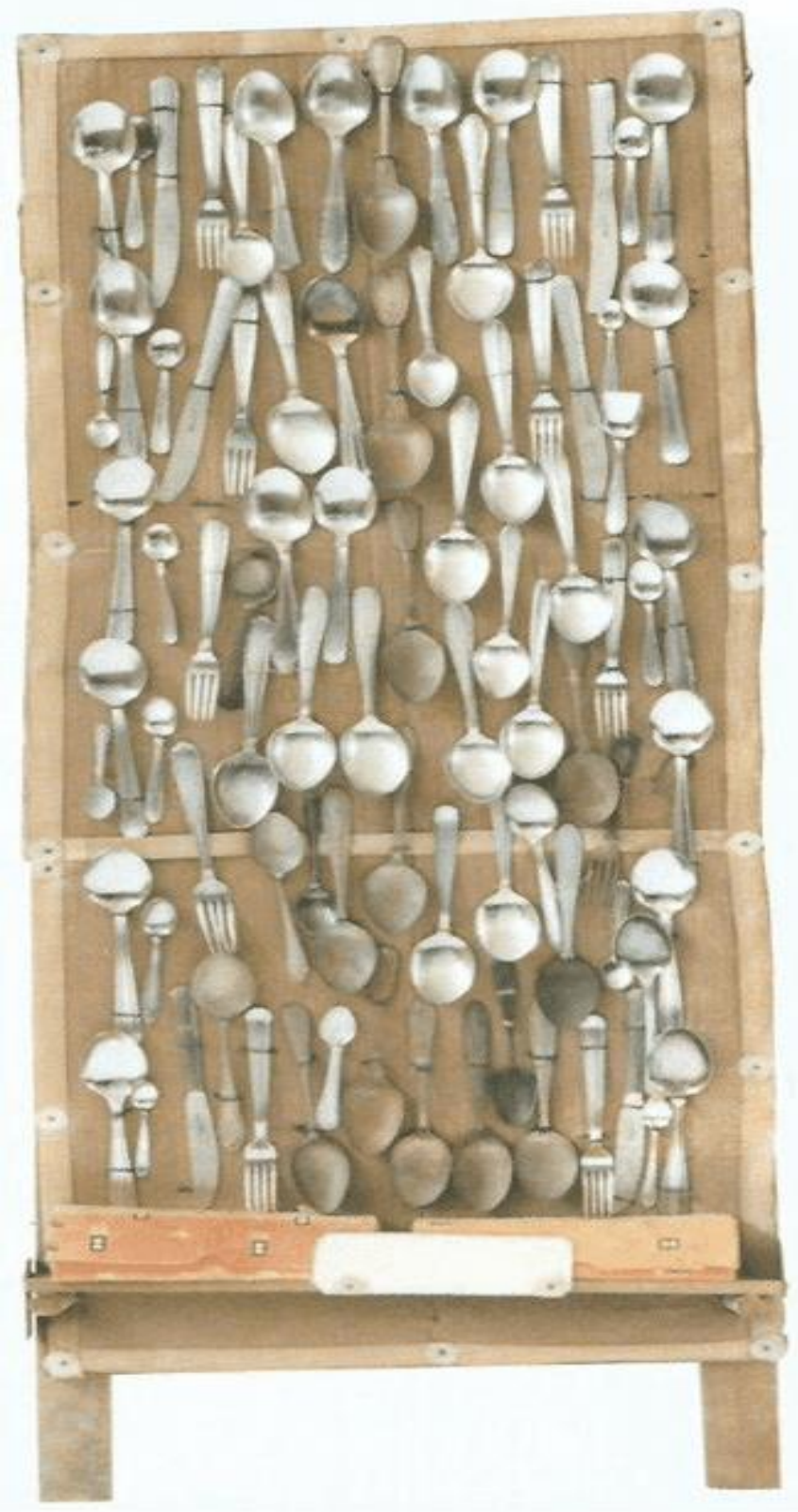

Fonte: DANTAS (2009, p. 155)

Na Figura 4, observa-se o senso de organização e ordenação presentes em Arthur Bispo do Rosário, ao relacionar, em um suporte de madeira e papelão, talheres de diversos modelos e tamanhos. 
Ordenar é o procedimento que imediatamente comunica a obra como organismo. A ordem, como disposição, exige um princípio lógico de categorias hierárquicas. Para que se chegue a resultados, em geral, previstos, buscam-se elementos reguladores sob os quais se coloca, por similaridade, aquilo que tem a mesma origem, a mesma forma física e a mesma cor. A natureza tem essa inteligência para a formação de categorias. (SILVA, 2003, p. 61)

Conforme Silva (2003), a qualidade de organizador em Bispo, não se restringia apenas à obra, mas também à sua própria vida comunitária na Colônia Juliano Moreira, atuando como líder e mediador, não somente na hora de distribuir alimentos e remédios. Dessa forma, sempre era procurado pelos outros internos, que thes traziam objetos para a composição de suas obras artísticas.

Assim, Arthur Bispo do Rosário transformou em obra de arte o fato de ordenar talheres por tamanho e tipo, assim como outros objetos, estabelecendo uma relação com a arte conceitual, desconhecida por ele.

FIGURA 5: "Vitrine-fichário" (s/d), tiras de linholene com o nome dos "escolhidos", suporte de papelão, s/medidas

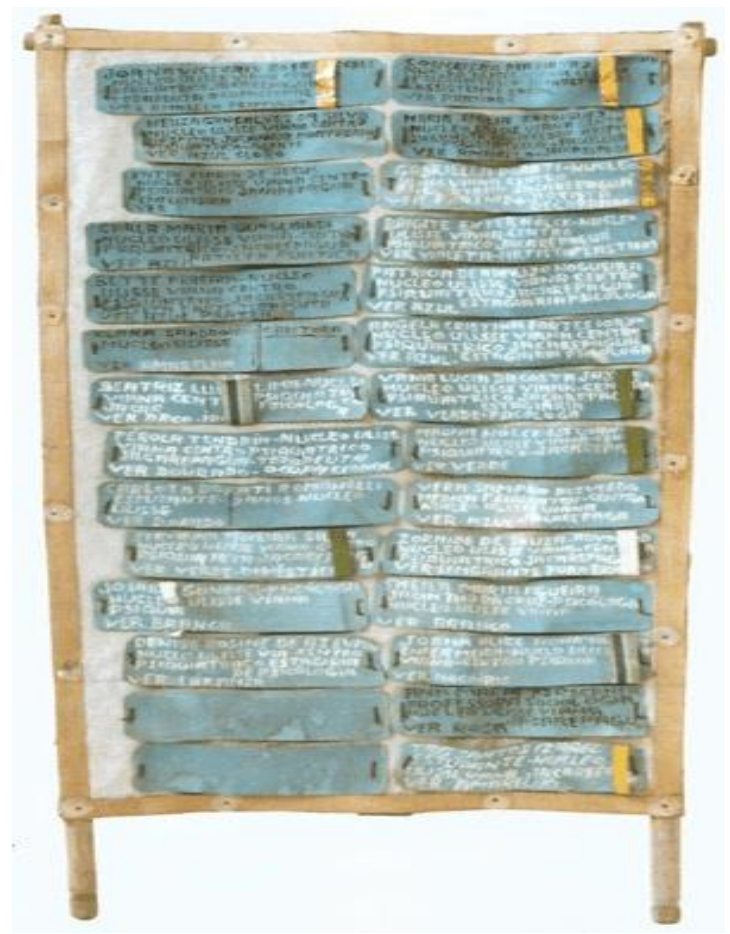

Fonte: DANTAS (2009, p. 171) 
Na Figura 5, há a catalogação dos nomes de escolhidos para que o acompanhassem no dia da passagem para o encontro com Deus, sendo pessoas que estava presentes em sua rotina na Colônia Juliano Moreira, como psicológicos, artistas plásticos e terapeutas ocupacionais.

"Não eram somente as coisas passíveis de catalogação, nomes de ruas e pessoas que deveriam acompanhá-lo no dia da "passagem", como é apresentado na Vitrinefichário." (DANTAS, 2009, p. 121)

Percebe-se assim, um inventário daqueles que "mereceriam" a passagem e a salvação, talvez por terem uma relação direta com Arthur Bispo do Rosário, despertando-Ihe confiança e afeição.

FIGURA 6: "Manto da Apresentação" (s/d), face externa, costas e vista da parte interna

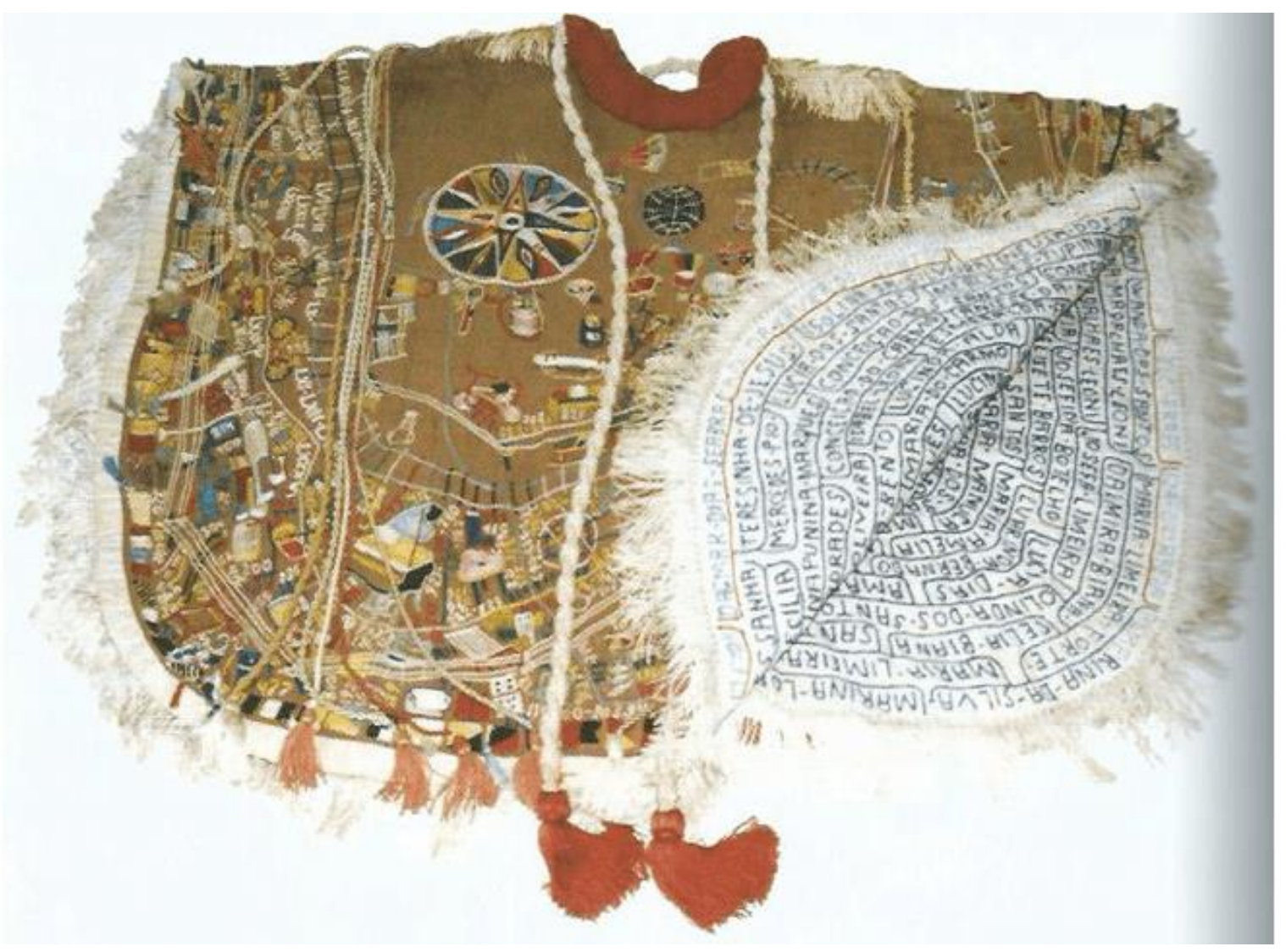

Fonte: DANTAS (2009, p. 202) 
Na Figura 6, há o "Manto de Apresentação", com o qual Arthur Bispo do Rosário faria a passagem para junto a Deus, sendo a sua obra mais emblemática.

Se a miss tem como atributos o cetro, a faixa e o manto, Bispo reserva para si apenas o símbolo maior da realeza: o Manto da passagem. Ele é o arabesco da loucura, o elemento aglutinador de toda a expressão e sentido da obra, com referenciais evidentes da vida do artista. É o objeto maior para a análise da obra e objetivo último da criação de Bispo. Realizado para o fim da transcendência, para a passagem do homem, significa a entrega à morte e a abertura das portas do reino da felicidade absoluta. (SILVA, 2003, p. 87)

Conforme Dantas (2009), o "Manto de Apresentação" foi confeccionado em dois tipos de tecido, sendo a face externa feita em cobertor, contendo palavras, símbolos, números e figuras bordados em fios de lã, em forma circular, apresentando também alamares e cordas de cortina como adornos. A face interna apresenta, sobre tecido branco, nomes de mulheres bordados de azul e em forma de espiral irregular.

Esse manto foi confeccionado para cobrir o corpo de Bispo no dia da sua "passagem", o dia do julgamento final. Ao vesti-lo, seria reconhecido por Deus e carregaria o mundo nos ombros; junto, carregaria todos aqueles que considerava "seus". (DANTAS, 2009, p. 207)

Segundo Dantas (2009), o "Manto da apresentação" contém elementos do barroco, conciliando a tradição cristã-católica-europeia com as culturas indígena e africana; sendo uma arte fundamentada no excesso e em contradições, como o bem e o mal, a opulência e a carência, o festivo e o trágico. Possui também uma relação com o Congo, um festejo popular que descende dos escravos, coroando um rei e rainha no dia da festa de Nossa Senhora do Rosário.

Com os Parangolés, Oiticica realiza a desmaterialização do objeto de arte, cria um não objeto. O Manto é, "naturalmente", um não objeto que, devido o seu grau de inventividade, pode ser tomado como objeto de arte. Como não objetos, tanto aqueles quanto este não necessitam da contemplação do espectador, mas, enquanto a "transmutação expressivo corporal" da obra de Oiticica depende do espectador que foi abolido em prol do participante, o Manto é objeto mágico e lúdico que permitia a transmutação de Bispo em rei dos reis. Em Parangolés é a arte que enriquece a vida; em Bispo, a vida foi transformada em arte. (DANTAS, 2009, p. 207) 
Percebe-se nessa obra a dedicação do artista e entrega à religiosidade e àquilo em que acreditava, revelando-se como um troféu a ser apresentado a Deus.

FIGURA 7: Arthur Bispo do Rosário com o "Manto da Apresentação"

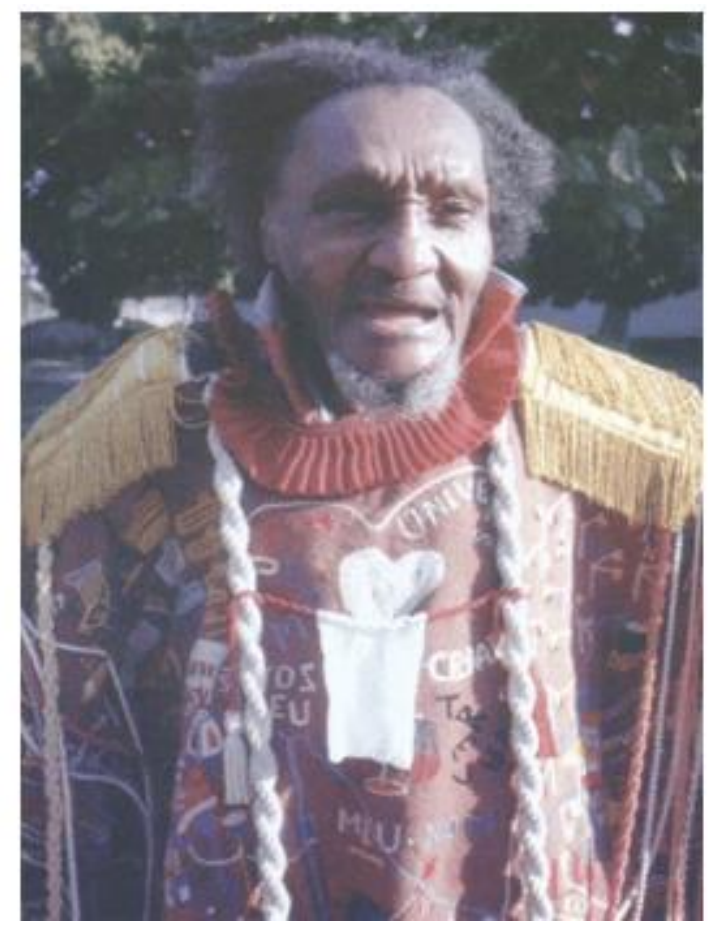

Fonte: HIDALGO (2011, p. 1; Fotografias)

"Contrariamente a quase toda a produção do artista, o Manto é pleno de movimento, em oposição ao caráter de embalsamento, fixidez e imobilidade de outros objetos." (SILVA, 2003, p. 90)

Pode ser vestido. Se a arte de Bispo pudesse transformar-Ihe a vida e não fosse uma representação apenas, isso ocorreria pelo Manto. Porque é o objeto que, em seu desejo, representa a passagem de uma situação determinada para outra, desconhecida. (SILVA, 2003, p. 90)

A Figura 7 apresenta Arthur Bispo do Rosário com a sua obra mais emblemática, revelando que o artista viveu plenamente o que acreditava, como se vestisse a sua crença e o seu propósito, revelando-se ao mundo através da sua arte. 


\subsection{A OBRA DE ARTHUR BISPO DO ROSÁRIO NO CENÁRIO ARTÍSTICO}

Conforme Silva (2003), Arthur Bispo do Rosário não se expressava visando à posteridade, sendo que grande parte de seus elementos possuem materiais não resistentes ao tempo, ou seja, a sua obra é efêmera, fugindo dos padrões de consumo. É considerada uma arte pobre, como foi conceituada a partir da década de 1950 essa arte expressiva e independente da sua base material, não se preocupando com a historicidade.

Impossibilitado de acompanhar as alterações sociais no mundo externo, privado de ver a evolução da arte extramuros, o artista voltou-se para a própria estrutura física da realidade asilar e, operando sobre ela, encontrou e fundamentou sua gama própria de bases materiais. (SILVA, 2003, p. 68)

Ainda de acordo com Silva (2003), para o artista contemporâneo, os materiais são coadjuvantes da ideia e não mais os determinantes. A obra de Bispo tem caráter inédito dentro de uma colônia de internos, sendo uma linguagem expressiva como fruto do psiquismo, tendo como temática a vida e seus acontecimentos.

Um jogo de interesses mútuos estofava a obra e qualquer contribuição adquiria novo sentido sob a lógica plástica de Bispo. Um dia seus objetos e bordados, estilhaços pós-modernos, seriam inseridos em classificações da crítica de arte, das vanguardas às neovanguardas. Ele apenas aliava o dom do artesão à rígida disciplina e, se sua missão divina um dia ganharia status de arte, comparada à obra de Marcel Duchamp, ele ignorava. (HIDALGO, 2011, p. 47)

Conforme Hidalgo (2011), ao acumular objetos manicomiais em suas obras, Bispo também confrontava o poder opressor do hospício, através de objetos sucateados e reorganizados conforme regras e estéticas diversas.

A lista de objetos que chegava ao quarto-forte de Bispo compunha uma espécie de espólio da Colônia. Uma infinidade de artigos de consumo do hospício, segregados em blocos. Naquele reduto de carências, não se entendia o amontoado de utensílios, peças do vestuário em exposição. O universo de Bispo não chegava a galerias de arte, marchands, 
mecenas. A avant garde dos circuitos de arte nova-iorquinos e europeus não chegava à Jacarepaguá. (HIDALGO, 2011, p. 82-83)

Segundo Silva (2003), há em Bispo uma similaridade com o ready made de Marcel Duchamp, que abstraiu o objeto de sua finalidade, revertendo-o em objeto artístico através do conceito gerado. O ready made de Duchamp é idealizado pelo trânsito da função e processado na forma de competência industrial, ao passo que Bispo se apropria e recupera o objeto destinado ao lixo, reintegrando-o ao universo das formas.

O caso de Bispo do Rosário é, mais uma vez, exemplar: de punhos cerrados ante a inesgotável tarefa de reconstruir o universo, Bispo nunca conseguiu sem dificuldade os materiais necessários para realizar sua viagem cósmica rumo ao grande dia da apresentação. (DIONISIO, 2012, p.112)

"Bispo tem uma complexidade formal inédita, entre loucos, e rara, mesmo entre artistas. Utiliza a forma na complexidade em que ela se apresentar. E não a criação direcionada por arte-terapeutas." (SILVA, 2003, p. 106)

Conforme Hidalgo (2011), através de uma reportagem do jornalista Samuel Wainer Filho com o cinegrafista Johnson Gouvêa, exibida no programa Fantástico da TV Globo, em 18 de maio de 1980,os problemas da Colônia Juliano Moreira foram denunciados e apresentados ao público, assim como Arthur Bispo do Rosário, o interno do pavilhão 10 do Ulisses Viana, e sua obra.

Ainda de acordo com Hidalgo (2011), em 1982, o psicanalista e fotógrafo Hugo Denizart editou o filme O prisioneiro da passagem - Arthur Bispo do Rosário, em $16 \mathrm{~mm}$, e o exibiu em congressos, debates e encontros no Brasil e no mundo, fazendo com que a obra de Arthur Bispo do Rosário saísse do domínio manicomial.

A pureza da vontade criativa desses artistas parece herdar um desígnio que pertence ao "inusitado", isto é, ao inesperado espanto (e mistério) que nos causam quando recebemos, apreendemos, admiramos suas obras. Somos, em verdade, capturados. (DIONISIO, 2012, p. 113)

Segundo Hidalgo (2011), Bispo entrou para o cenário artístico através da exposição "À margem da vida", organizada pela artista plástica Maria Amélia Mattei, exibida entre julho e agosto de 1982, no Museu de Arte Moderna (MAM) do Rio de Janeiro, com os 
trabalhos de internos dos institutos penais Lemos de Brito e Milton Dias Moreira, da Fundação Nacional para o Bem-Estar do Menor (Funabem), da Casa São Luiz para a Velhice e da Colônia Juliano Moreira.

Apenas em 1989, de acordo com Hidalgo (2011), após o falecimento de Bispo, foi realizada a exposição "Registros de minha passagem pela Terra", sob a curadoria de Frederico Morais, na Escola de Artes Visuais do Parque Lage, no Rio de Janeiro, em que houve o seu reconhecimento como artista pós-moderno. A partir daí, seguiramse diversas reportagens sobre Arthur Bispo do Rosário.

Conforme Hidalgo (2011), em 1991, a obra de Arthur Bispo do Rosário foi apresentada na Suécia, ocupando uma sala especial na mostra "Viva Brasil Viva", no centro cultural Kulturhuset, em Estocolmo.

"Em 25 de novembro de 1992, a Secretaria de Cultura do Estado do Rio de Janeiro, por meio do Instituto Estadual de Patrimônio Artístico e Cultural, decretou o tombamento integral da obra de Bispo." (HIDALGO, 2011, p. 179)

Ainda de acordo com Hidalgo (2011), a obra de Arthur Bispo do Rosário foi escolhida para representar o Brasil, junto à do artista plástico Nuno Ramos, na 46 Bienal de Veneza, inaugurada em junho de 1995. Atualmente, o Museu Nise da Silveira, no Rio de Janeiro, é denominado Museu Bispo do Rosário.

Todos esses destaques foram importantes para que a obra de Bispo pudesse ser conhecida e divulgada mundialmente, levando à reflexão sobre a sua condição como interno da Colônia Juliano Moreira e possuidor de uma obra única, valorizado no cenário artístico e acadêmico.

\section{CONSIDERAÇÕES FINAIS}

A Estética, analisada através da narrativa de Hegel, compreende que as obras de arte são produtos criados pelo homem e dirigem-se ao mundo sensível, não sendo um produto da natureza. Para Suassuna, a Estética não se confunde com a Crítica da 
Arte, sendo apenas uma atividade reflexiva sobre a Beleza e a Arte, e não sobre aquilo que é apenas concreto.

A Estética Relacional de Bourriaud propõe que o artista produz objetos através de uma interação dele com o mundo, estabelecendo relações.

A obra de Arthur Bispo do Rosário não possuía um ideal estético ou acadêmico, tendo como base a sua religiosidade, caracterizada com o objetivo de "servir a uma missão", aproveitando-se dos materiais de uso cotidiano, que recebia ou encontrava, dentro do hospital psiquiátrico, estabelecendo relações subjetivas entre o que acreditava, suas memórias e o ambiente que vivia.

Através das narrativas de Dantas, Dionisio, Foucault, Hidalgo, Lazaro e Silva, foi analisada a obra de Arthur Bispo do Rosário, assim como os elementos que a compõem.

A obra de Arthur Bispo do Rosário, diagnosticado com esquizofrenia paranoide, continha elementos de ordenação, catalogação, preenchimento e envolvimento, percebidos na forma como organizava objetos, narrava fatos e citava os nomes de pessoas próximas. A religiosidade e o fato de criar um inventário do mundo como bagagem para o encontro com Deus, criam os elementos únicos de sua poética, transformadora de objetos simples em obras de arte.

O fato de Arthur Bispo do Rosário criar objetos a partir de sucatas e coisas que estavam ao seu redor, incluindo toda a temática e extensão da sua obra, fez com que fosse reconhecido como artista pós-moderno e de ligação com a arte conceitual, não somente no Brasil como no exterior.

Porém, Bispo não tinha a noção de que era artista e da importância de sua obra, que realizava para si mesmo e as mostrava apenas para aqueles que conseguiam entrar em seu universo onírico.

Foi possível constatar que o meio cultural em que o artista vivia influenciou a sua obra, assim como as suas memórias da Marinha e os elementos da infância, possibilitando 
a criação dos bordados. A esquizofrenia paranoide fazia com que vivesse em um universo único, em que a religiosidade era o seu maior estandarte, mas sem deixar que percebesse o cotidiano e aproveitasse os elementos que estavam a sua volta para se expressar e transmitir ao mundo o legado de suas memórias e crenças.

\section{REFERÊNCIAS}

BOURRIAUD, Nicolas. Estética Relacional. Tradução de Denise Bottmann. São Paulo: Martins Fontes, 2009.

DANTAS, Martha. Arthur Bispo do Rosário: a poética do delírio. São Paulo: UNESP, 2009.

DIONISIO, Gustavo Henrique. O antídoto do mal: crítica de arte e loucura na modernidade brasileira. Rio de Janeiro: FIOCRUZ, 2012.

FOUCAULT, Michel. História da Loucura na Idade Clássica. Tradução de José Teixeira Coelho Netto. São Paulo: Perspectiva, 1978.

HEGEL, Georg Wilhelm Friedrich. Curso de Estética: o belo na arte. Tradução de Orlando Vitorino e Álvaro Ribeiro. São Paulo: Martins Fontes, 1996.

HIDALGO, Luciana. Arthur Bispo do Rosário: o senhor do labirinto. 2. ed. Rio de Janeiro: Rocco, 2011.

LAZARO, Wilson (Org.). Arthur Bispo do Rosário. Rio de Janeiro: Réptil, 2012. 304 p.

SILVA, Jorge Anthonio e. Arthur Bispo do Rosário: arte e loucura. 2. ed. São Paulo: Quaisquer, 2003.

SUASSUNA, Ariano. Iniciação à Estética. 9. ed. Rio de Janeiro: José Olympio, 2008.

Enviado: Julho, 2020. 
Aprovado: Novembro, 2020. 